\title{
Review of Literatures: Physiology of Orofacial Pain in Dentistry
}

\author{
- Nattapon Rotpenpian, ${ }^{1}$ and Pankeaw Yakkaphan $^{2}$
}

https://doi.org/10.1523/ENEURO.0535-20.2021

${ }^{1}$ Department of Oral Biology and Occlusion, Faculty of Dentistry, Prince of Songkla University, Songkhla, Thailand 90110 and ${ }^{2}$ Department of Oral Diagnostic Science, Faculty of Dentistry, Prince of Songkla University, Songkhla, Thailand 90110

\begin{abstract}
The objective of this review of the literature is to summarize the physiology of orofacial pain in dentistry, particularly physiology of the pain pathway and molecular mechanisms on pathophysiology of pain, on account of new insights into classification of orofacial pain related diseases. This article will also focus on possible mechanisms of neuropathic orofacial pain which is distinguished from other types of pain.
\end{abstract}

Key words: dentistry; neurophysiology; orofacial pain; pain; sensation; sensory function

\section{Introduction}

Pain is a sensory modality that is an unpleasant and emotional experience (Pak et al., 2018). Painful sensation is subjective and biologically useful, necessary for survival, being a warning sign and response of damaged tissue in the body (John, 1990; Rivera-Morales, 1986). Pain in the facial area is the most common reason which brings patients to see a dentist (Piovesan et al., 2003). Orofacial pain is pain associated with the hard and soft tissues of the head, face, and oral cavity (Sessle, 1987). There are diverse and several mechanisms related to this pathology (Sessle, 1987). Therefore, orofacial pain physiology should be elucidated and applied to clinical practice in the future. This review will define the physiology of orofacial pain and classification of orofacial pain in dentistry. In this review, the strategy for the search in terms of pain, pathophysiology of pain, orofacial pain, dental pain, nociceptive pain, neuropathic pain, pain pathway, and the publication year is $1980-2021$.

Received December 9, 2020; accepted March 23, 2021; First published April 2, 2021.

The authors declare no competing financial interests.

Author contributions: N.R. and P.Y. wrote the paper.

This work was supported by Faculty of Dentistry, Prince of Songkla University, Thailand.

Correspondence should be addressed to Nattapon Rotpenpian at nattapon. r@psu.ac.th.

https://doi.org/10.1523/ENEURO.0535-20.2021

Copyright ( ) 2021 Rotpenpian and Yakkaphan

This is an open-access article distributed under the terms of the Creative Commons Attribution 4.0 International license, which permits unrestricted use, distribution and reproduction in any medium provided that the original work is properly attributed.

\section{Physiology of the Orofacial Pain Pathway}

The orofacial region is composed of the oral cavity (teeth, gingiva, and oral mucosa), face, jaw bone, and temporomandibular joint (Messlinger and Handwerker, 2015). Physiology of orofacial pain pathways includes primary afferent neurons, pathologic changes in trigeminal ganglion, brainstem nociceptive neurons, and higher brain function regulating orofacial nociception.

\section{Primary Afferent Neurons and Pathologic Changes in Trigeminal Ganglion}

The trigeminal nerve or cranial nerve $\mathrm{V}(\mathrm{CN} \mathrm{V})$ is a sensory nerve which innervates this region. The trigeminal pain pathway from the orofacial area is represented in Figure 1. At the peripheral nociceptors in the orofacial region, after receiving repetitive noxious stimuli or an excessive uncontrollable inflammation, the first order neurons in the trigeminal nerve will develop increased pain signals that are projected to the trigeminal ganglia (Huff and Daly, 2020). The trigeminal ganglia is similar to the dorsal root ganglia (Armstrong and Herr, 2020).

\section{Brainstem Nociceptive Neurons}

After that, the pain signals are sent to the second order neurons in the trigeminal nucleus caudalis located in the brainstem. The trigeminal nucleus caudalis is similar to the dorsal horn of the spinal cord and contains second order neurons.

For the trigeminal nucleus, there are three groups of nuclei located inside the brainstem (Joseph, 1982; RiveraMorales, 1986; John, 1990; Wilkinson, 2014). The first spinal nucleus of the CN V is the pars oralis and the second 


\section{Overview Oro-facial pain physiology}

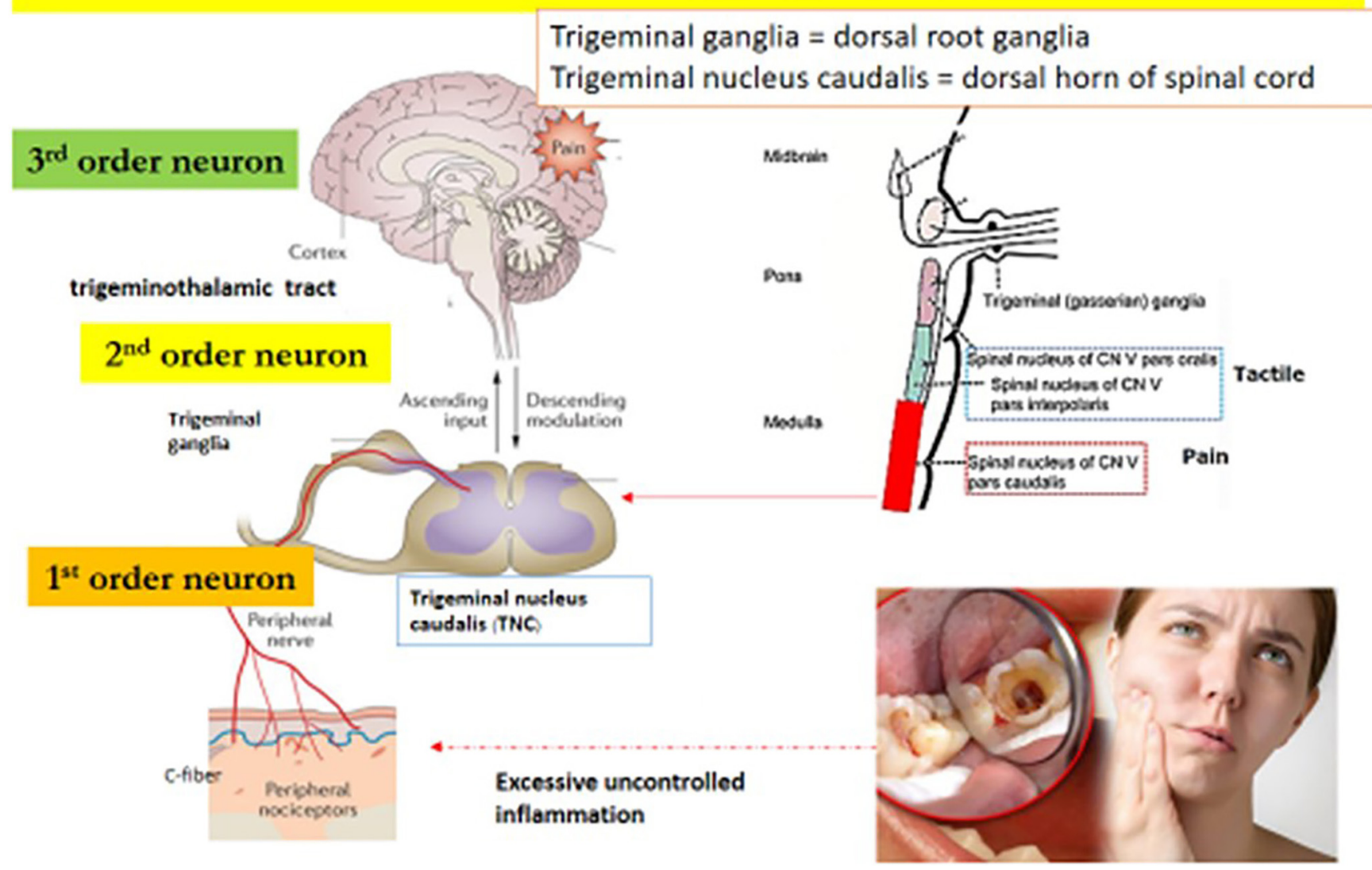

Figure 1. Overview of orofacial pain physiology.

is the par interpolaris. Both of them convey a tactile sensation in the orofacial area. The third spinal nucleus of the $\mathrm{CN} \mathrm{V}$ is the pars caudalis or trigeminal nucleus caudalis (Christoforou, 2018; Klasser et al., 2018) which carries the pain perception of this involved area. Then the signals will be further projected to the third order neurons in the thalamus via the ventral trigeminothalamic tract (Joseph, 1982; Rivera-Morales, 1986; John, 1990; Roberts, 1991; van der Bilt et al., 2006; Wilkinson, 2014; Badel et al., 2019).

\section{Higher Brain Function Regulating Orofacial Nociception}

In the everse mechanism, there is a descending pathway or pain modulation process from the somatosensory cortex to the trigeminal nucleus caudalis (Sessle, 1987). Naturally, the brainstem perceives ascending sensory input and sends the signal to the thalamus and cortex respectively (Woolf and American Physiological Society, 2004). However, the neurons of the brainstem can also modulate the pain pathway by sending somatosensory signals through the periaqueductal gray, locus coeruleus and rostral ventromedial medulla. Periaqueductal gray is the central midbrain neurons and modulates pain pathways indirectly via other brainstem nucleus, including the locus coeruleus and rostral ventromedial medulla. The locus coeruleus is composed of noradrenergic neurons which are projected to the trigeminal nucleus caudalis. The rostral ventromedial medulla is a large region of medulla which is placed by serotoninergic neurons (ArendtNielsen et al., 2018). The descending pathway sends signals to the trigeminal nucleus caudalis. Either serotonin and norepinephrine are released or enkephalin or opioid peptides are produced: this process leads to pain reduction (Fields, 1987; Espinosa-Sanchez et al., 2020). A clinical study reported that patients experiencing temporomandibular joint pain might have a decrease in neurons on both sides of the brainstem, especially at the rostral ventromedial, which is responsible for descending pain pathways or pain modulation. Therefore, the reduction of neurons in the descending pain modulation might increase pain sensation in patients with painful temporomandibular disorders (Wilcox et al., 2015).

Therefore, numerous studies supported that the pathophysiology of orofacial pain is related to the trigeminal nerve and trigeminal pathway leading to alter pain perception in the relevant area of the somatosensory cortex and associated somatosensory cortex.

\section{Classification of Orofacial Pain and Possible Mechanisms}

The classification of orofacial pain concerned by durations can be divided into acute pain and chronic pain. By 


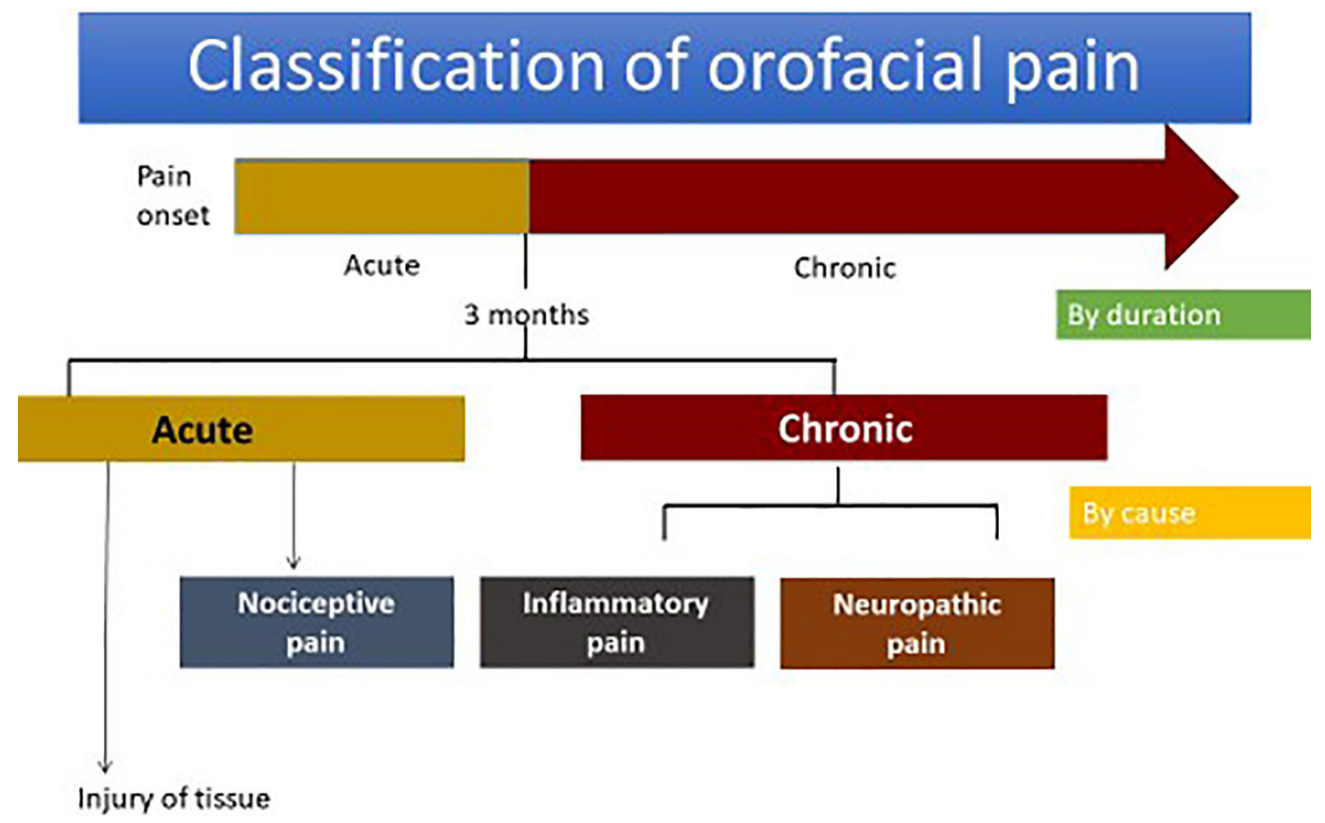

Figure 2. Classification of orofacial pain.

causes, it can be categorized into nociceptive, inflammatory and neuropathic pain (Lee et al., 2005; Fig. 2)

Acute orofacial pain is the sudden onset of pain related to physical sensations and possibly of limited duration as well as being temporary because of tissue injury causes. Chronic orofacial pain is long lasting pain beyond three months, which is the normal healing period of time (Bell, 1989; Buxbaum, 1994; Christopher, 1998; Monheim, 2019). The difference of acute and chronic orofacial pain is shown in Table 1.

Another classification of orofacial pain is classified by three causative groups; nociceptive, inflammatory and neuropathic pain. Nociceptive pain is pain that occurs when noxious stimuli such as heat, cold, intense mechanical force, and chemical irritants directly stimulate nociceptive sensory neurons. Then the nociceptors send signals to the central nervous system leading to pain response such as withdrawal reflex. Therefore, nociceptive pain mechanisms obviously act as a vital physiological sensation (Ananthan and Benoliel, 2020). Inflammatory pain is a pain caused by damaged tissues. Once tissues are injured, the release of inflammatory mediators subsequently occurs and activates pain perception (Shinoda et al., 2019). Neuropathic pain is a pain caused by defects in the peripheral or central nervous system (Fehér et al., 2019; Jaaskelainen, 2019). Thus, the differences between nociceptive, inflammatory and neuropathic pain are shown in Table 2.

Orofacial neuropathic pain originates from disorders of the somatosensory system. Results of injury to the nerves involved the pain pathway and maybe considered as chronic pain conditions (Jaaskelainen, 2004).

Table 1. Difference in acute orofacial pain and chronic pain orofacial pain

\begin{tabular}{|c|c|c|}
\hline Characteristics & Acute orofacial pain & Chronic orofacial pain \\
\hline Duration & Onset & Sustained, persistent $>3$ months in humans \\
\hline Cause & Caused by inflammation or injury of tissue & $\begin{array}{l}\text { Caused by inflammation, nerve damage and exces- } \\
\text { sive or uncontrolled inflammation }\end{array}$ \\
\hline Cause has gone away or healed & $\begin{array}{l}\text { No pain when normal healing occurs or is } \\
\text { only temporary (pain disappears once } \\
\text { stimulus is removed) }\end{array}$ & Persistent pain and excessive, uncontrolled causes \\
\hline Signs and symptoms & Sudden, sharp, intense, localized & Aching, diffused \\
\hline Physiologic response & $\begin{array}{l}\text { Acute pain affects increased cardiovascular } \\
\text { functions such as increased blood pres- } \\
\text { sure and heart rate via sympathetic } \\
\text { response }\end{array}$ & $\begin{array}{l}\text { Chronic pain affects physiological } \\
\text { responses with adaptation behaviors or psycho- } \\
\text { logical responses such as depression and anxiety }\end{array}$ \\
\hline Examples in the orofacial area & $\begin{array}{l}\text { (1) Dental pain: pulpitis } \\
\text { (2) Mucogingival pain }\end{array}$ & $\begin{array}{l}\text { (1) Neuropathic pain: trigeminal neuralgia, peripheral } \\
\text { trigeminal nerve injury, postherpetic neuralgia } \\
\text { (2) Chronic inflammatory pain: chronic pulpitis and } \\
\text { apical lesions, temporomandibular disorder pain } \\
\text { (3) Neurovascular pain: migraines, tension-type } \\
\text { headaches }\end{array}$ \\
\hline
\end{tabular}


Table 2. Difference between nociceptive, inflammatory, and neuropathic pain

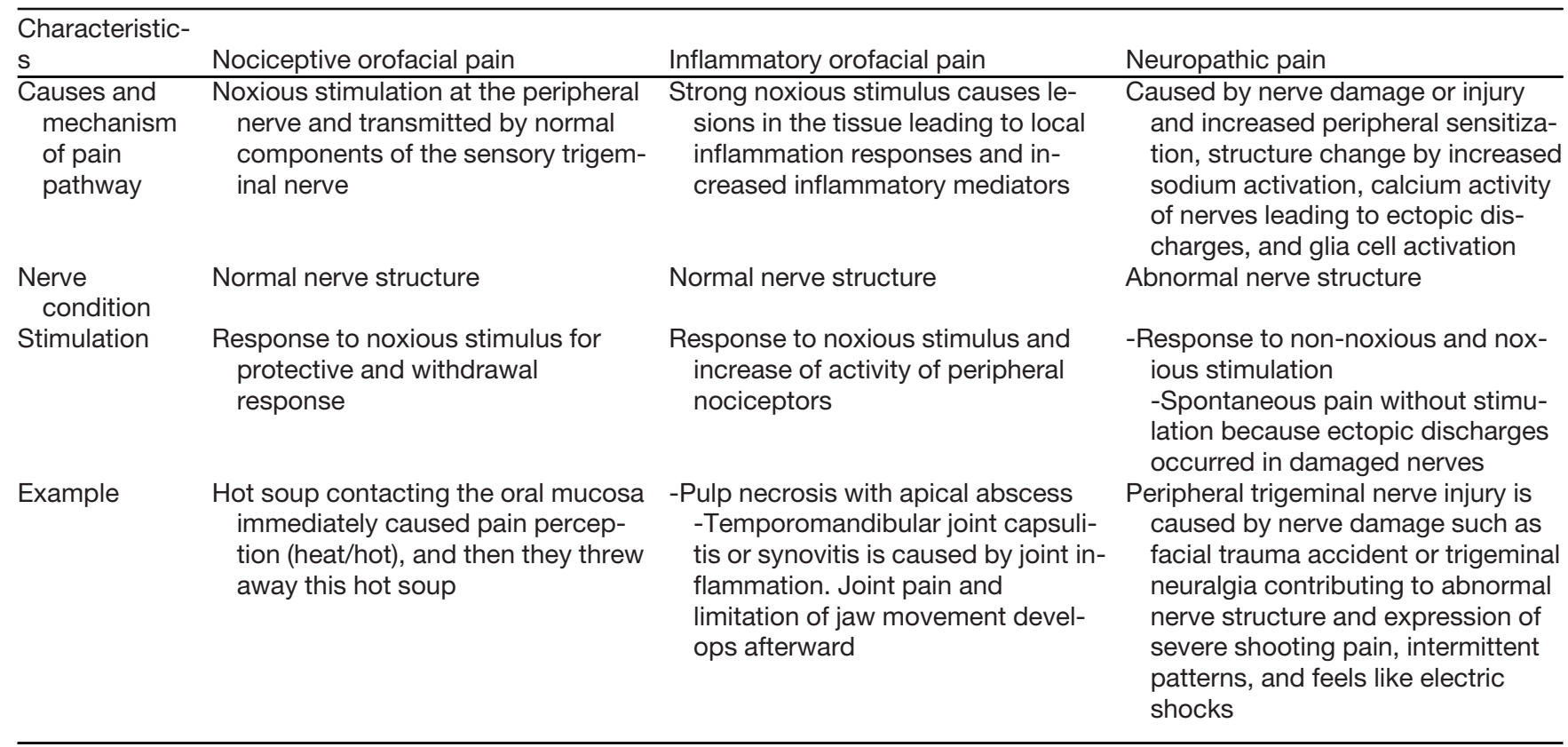

The mechanisms of neuropathic pain are distinct from other types of orofacial pain (Fig. 3).

The possible mechanisms of orofacial neuropathic pain are distinguishable from nociceptive and inflammatory pain. After trigeminal nerves are damaged, the neuroma or injured axon around the damaged site proliferate heterotopic sodium channels such as voltage gated channel types 1.3, 1.7, and 1.8 (Allard et al., 2006; Hargus and
Patel, 2007). The proliferation of sodium channels may cause lower stimulation thresholds and provoke ectopic discharges (Li et al., 2015). The spread of sodium channels triggers central sensitization at the trigeminal nucleus caudalis and leads to an enhanced barrage of nociceptive signals, which results in spontaneous pain and pain hypersensitivity (Piovesan et al., 2003; Bernal and Roza, 2018).

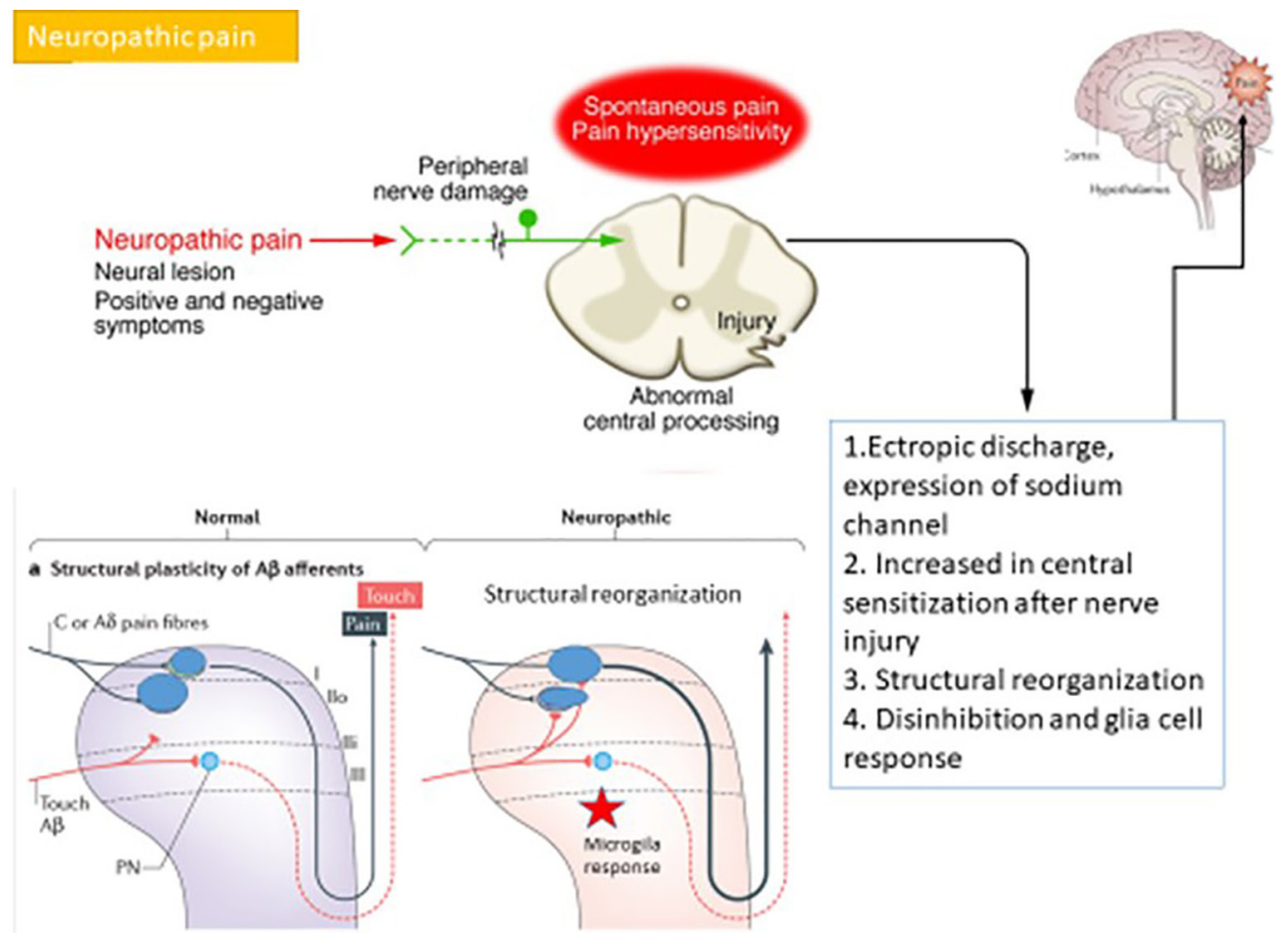

Figure 3. The possible mechanisms of neuropathic pain. 
The alteration of the calcium channel in the primary afferent nociceptors leads to enhanced transmitters which are released into the trigeminal nucleus caudalis ( $\mathrm{Li}$ et al., 2019). In addition, AMPA receptors activate trigeminal nucleus caudalis neurons that are related to common responses to painful stimuli, but NMDA receptors are physiologically blocked by a magnesium ion. This blockage is likely removed by accumulation or repetitive depolarization from ectopic discharges. Alteration of the calcium channel results in an amplification and prolongation of the noxious input in the trigeminal nucleus caudalis inside the brainstem (Yam et al., 2018; Armstrong and Herr, 2019).

Furthermore, after nerve injury, the peripheral nerve lesion causes axon and myelin sheath degradation which is later followed by infiltration of macrophages and other types of immune cells such as neutrophils and T cells at the injured site (Spencer and Gremillion, 2007; Lebrilla and Mahal, 2009; Todd, 2010). Moreover, nerve damage subsequently generates functional modulation and modification of the central nervous system (Boadas-Vaello et al., 2017).

Functional modulation after nerve injury leads to increased posttranslational processing such as c-fos in the trigeminal nucleus caudalis. Moreover, the coupling between sympathetic postganglionic neurons and afferent neurons under pathophysiological conditions can occur to maintain pain. Modification after nerve injury is altered in connectivity and cell death by some adjacent uninjured nerve fibers which become excited because of non-synaptic or cross talk of electrical transfers called ephaptic transmission. Finally, this modulation and modification function causes an increase in central sensitization in the trigeminal nucleus caudalis and subsequently the recruitment of secondary messenger pathways after central sensitization results in a rise of neuron excitability or nociceptors or pain signals to the thalamus and somatosensory cortex (Yam et al., 2018; Dolphin et al., 2020).

Non-injury state in the area of the trigeminal nucleus caudalis and dorsal horn of the spinal cord, $A \beta$ fibers penetrate to the dorsal horn, travel ventrally and terminate in Lamina II and deeper into the spinal cord. However, after the peripheral nerve is damaged or injured (Nelson, 2019), there is c-fiber terminal atrophy and A fiber terminal sprouting into the superficial dorsal horn, which conducts easier stimulation of pain signals in the dorsal horn of the spinal cord, and is the reason why non-painful stimulators can produce pain responsiveness in allodynia (Song et al., 2013).

In addition, after nerve injury, a loss of inhibition occurs because of dysfunction of GABA production and apoptosis of inhibitory interneurons resulting in reduction of inhibition pain signals (Tashiro et al., 2014). Lack of or a decrease in inhibition pain signals cause an increased excitability of neurons (Yin et al., 2018). Moreover, after prolonged nerve injury, there follows a decrease in pain modulation of descending pain pathways which result in more nociceptive signals in the pain pathway (Sessle, 2011).

Therefore, the possible pain mechanisms related to glia cell response after nerve injury are caused by microglial activation. Microglia can then release pro-inflammatory mediators such as interleukin 6 , interleukin $1 \beta$, and tumor necrosis factor $\alpha$, and activate astrocytes (Han et al., 2012; Won et al., 2012; Lemos et al., 2018). Activated astrocytes or reactive astrocytes directly trigger NMDA receptors (Zhou et al., 2019) leading to excess glutamate release to the trigeminal nucleus caudalis and increase pain signaling projected to the brain and development of neuropathic pain (Jancalek, 2011; Mamoru et al., 2011; Eftekhari et al., 2015).

Chronic neuropathic orofacial pain manifests many distinct functions and possible mechanism apart from inflammatory pain (Tandon et al., 2003) Nevertheless, the differential diagnosis should be performed and defined these types of pain because of different pain management (Allegri et al., 2012).

Consequence, if orofacial pain (acute/chronic stages), which is not neuropathic pain, does not produce an ectopic discharge, structural reorganization and glia cell response. This process of inflammatory pain is sustained by chemical inflammation at the primary trigeminal afferents neuron such as substance $P$, bradykinin, and calcitonin related peptide proteins leading to peripheral sensitization of peripheral nociceptors at the lesion (Tandon et al., 2003; Allegri et al., 2012). However, repetitive stimulation of c-fibers via the inflammation or nerve injury stimulates a gradual increase of neuron excitability or winds them up, causing central sensitization. Evidence showed that blockading NMDA receptors could attenuate chronic inflammatory or neuropathic pain in animal models (Wong et al., 2014; Lin et al., 2019; Neyama et al., 2020). Subsequently, its mechanism can drive central hyper excitability by chemical mediators and other peptides that remove the magnesium-ion block of NMDA receptors at the trigeminal nucleus caudalis, which could possibly increase pain perception (Koichi et al., 2011).

Currently, there is another name of pain classification which called "nociplastic pain." Nociplastic pain is meant an un-classification of pain or not properly covered by nociceptive pain or neuropathic pain. Therefore, nociplastic pain is caused by an altered nociceptive function but not inflammatory responses. An example of nocociplastic pain is persistent idiopathic dentoalveolar pain, previously known as atypical odontalgia. Persistent idiopathic dentoalveolar pain is a chronic pain condition that shows as a persistent tooth, alveolar bone, gingiva although undetectable pathology during clinical or radiologic examination (Aydede and Shriver, 2018). However, the pathophysiology of nociplastic pain is still unclear, further study about nociplastic pain should be investigated.

\section{Conclusion}

Orofacial pain has become more problematic among the general population. The anatomic complexity of the orofcial region contributes to challenging diagnosis and treatment for many clinicians. A better understanding of underlying physiological mechanisms on orofacial pain may support to improve a clinician's clarification and perception in the aspect of non-odontogenic or dental pain origin. 


\section{References}

Allard B, Magloire H, Couble ML, Maurin JC, Bleicher F (2006) Voltage-gated sodium channels confer excitability to human odontoblasts: possible role in tooth pain transmission. J Biol Chem 281:29002-29010.

Allegri M, Clark MR, De Andrés J, Jensen TS (2012) Acute and chronic pain: where we are and where we have to go. Minerva Anestesiol 78:222-235.

Ananthan S, Benoliel R (2020) Chronic orofacial pain. J Neural Transm (Vienna) 127:575-588.

Arendt-Nielsen L, Morlion B, Perrot S, Dahan A, Dickenson A, Kress HG, Wells C, Bouhassira D, Mohr Drewes A (2018) Assessment and manifestation of central sensitisation across different chronic pain conditions. Eur J Pain 22:216-241.

Armstrong SA, Herr MJ (2019) Physiology, nociception. Treasure Island: StatPearls Publishing LLC.

Armstrong SA, Herr MJ (2020) Physiology, nociception. Treasure Island: StatPearls Publishing LLC.

Aydede M, Shriver A (2018) Recently introduced definition of "nociplastic pain" by the International Association for the Study of Pain needs better formulation. Pain 159:1176-1177.

Badel T, Zadravec D, Bašić Kes V, Smoljan M, Kocijan Lovko S, Zavoreo I, Krapac L, Anić Milošević S (2019) Orofacial pain - diagnostic and therapeutic challenges. Acta Clin Croat 58:82-89.

Bell WE (1989) Orofacial pains; classification, diagnosis, management, Ed, 4. Chicago: Year Book Medical Publishers Inc.

Bernal L, Roza C (2018) Hyperpolarization-activated channels shape temporal patterns of ectopic spontaneous discharge in C-nociceptors after peripheral nerve injury. Eur J Pain 22:1377-1387.

Boadas-Vaello P, Homs J, Reina F, Carrera A, Verdú E (2017) Neuroplasticity of supraspinal structures associated with pathological pain. Anat Rec (Hoboken) 300:1481-1501.

Buxbaum JD (1994) Dental management of orofacial pain. In: Hand book of pain management (Tollison CDSJ, Tollison JW, eds), 2nd Ed 2, pp 306-327. Baltimore: Williams and Wikins.

Christoforou J (2018) Neuropathic orofacial pain. Dent Clin North Am 62:565-584.

Christopher LB (1998) Applied oral physiology, Ed 2. London: Wright.

Dolphin AC, Insel PA, Blaschke TF, Meyer UA (2020) Introduction to the theme "ion channels and neuropharmacology: from the past to the future". Annu Rev Pharmacol Toxicol 60:1-6.

Eftekhari S, Salvatore CA, Johansson S, Chen TB, Zeng Z, Edvinsson L (2015) Localization of CGRP, CGRP receptor, PACAP and glutamate in trigeminal ganglion. Relation to the blood-brain barrier. Brain Res 1600:93-109.

Espinosa-Sanchez JM, Espinosa-Campos L, Batuecas-Caletrío Á (2020) From neuroanatomy to neurophysiology. Anat Rec (Hoboken) 303:1221-1231.

Fehér G, Nemeskéri Z, Pusch G, Zádori I, Bank G, Gurdán Z, Mészáros J, Mák K, Tibold A, Komoly S (2019) Chronic orofacial pain. Orv Hetil 160:1047-1056.

Han SR, Yang GY, Ahn MH, Kim MJ, Ju JS, Bae YC, Ahn DK (2012) Blockade of microglial activation reduces mechanical allodynia in rats with compression of the trigeminal ganglion. Prog Neuropsychopharmacol Biol Psychiatry 36:52-59.

Hargus NJ, Patel MK (2007) Voltage-gated $\mathrm{Na}+$ channels in neuropathic pain. Expert Opin Investig Drugs 16:635-646.

Fields HL (1987) Pain. New York: McGraw-Hill.

Huff T, Daly DT (2020) Neuroanatomy, cranial nerve 5 (trigeminal). Treasure Island: StatPearls Publishing LLC.

Jaaskelainen SK (2004) Clinical neurophysiology and quantitative sensory testing in the investigation of orofacial pain and sensory function. J Oro Pain 18:85-107.

Jaaskelainen SK (2019) Differential diagnosis of chronic neuropathic orofacial pain: role of clinical neurophysiology. J Clin Neurophysiol 36:422-429.

Jancalek R (2011) Signaling mechanisms in mirror image pain pathogenesis. Ann Neurosci 18:123-127.
John J (1990) The management of pain, Ed 2. Philadelphia: Lea and Febiger.

Joseph G (1982) Correlative neuroanatomy and functional neurology, Ed 18. California: Lange Medical Publications.

Klasser GD, Almoznino G, Fortuna G (2018) Sleep and orofacial pain. Dent Clin North Am 62:629-656.

Koichi I, Yoshiki I, Kuniya H, Masamichi S (2011) Physiological mechanisms of neuropathic pain: the orofacial region. Int Rev Neurobiol 97:227-250.

Lebrilla CB, Mahal LK (2009) Post-translation modifications. Curr Opin Chem Biol 13:373-374.

Lee Y, Lee CH, Oh U (2005) Painful channels in sensory neurons. Mol Cells 20:315-324.

Lemos GA, da Silva PLP, Batista AUD, Palomari ET (2018) Experimental model of temporomandibular joint arthritis: evaluation of contralateral joint and masticatory muscles. Arch Oral Biol 95:79-88.

Li G, Liu X, Du J, Chen J, She F, Wu C, Li C (2015) Positive shift of Nav1.8 current inactivation curve in injured neurons causes neuropathic pain following chronic constriction injury. Mol Med Rep 12:3583-3590.

Li XH, Miao HH, Zhuo M (2019) NMDA receptor dependent longterm potentiation in chronic pain. Neurochem Res 44:531-538.

Lin W, Zhao Y, Cheng B, Zhao H, Miao L, Li Q, Chen Y, Zhang M (2019) NMDAR and JNK activation in the spinal trigeminal nucleus caudalis contributes to masseter hyperalgesia induced by stress. Front Cell Neurosci 13:495.

Mamoru T, Shigeji M, Barry JS, Masamichi S, Koichi I (2011) Peripheral and central mechanisms of trigeminal neuropathic and inflammatory pain. J Oral Biosci 53:318-329.

Messlinger K, Handwerker HO (2015) Physiology of pain. Schmerz 29:522-530.

Monheim LM (2019) Analgesia in dentistry now and in the future. Anesth Prog 66:227-231.

Nelson TS (2019) Dorsal horn PKC $\gamma$ interneurons mediate mechanical allodynia through 5-HT2AR-dependent structural reorganization. J Neurosci 39:6221-6223.

Neyama H, Dozono N, Ueda H (2020) NR2A-NMDA receptor blockade reverses the lack of morphine analgesia without affecting chronic pain status in a fibromyalgia-like mouse model. J Pharmacol Exp Ther 373:103-112.

Pak DJ, Yong RJ, Kaye AD, Urman RD (2018) Chronification of pain: mechanisms, current understanding, and clinical implications. Curr Pain Headache Rep 22:9.

Piovesan EJ, Kowacs PA, Oshinsky ML (2003) Convergence of cervical and trigeminal sensory afferents. Curr Pain Headache Rep 7:377-383.

Rivera-Morales WC (1986) Orofacial pains; classification, diagnosis, management, Ed 4. Chicago: Year Book Medical Publishers Inc.

Roberts GJ (1991) A colour atlas of dental analgesia and sedation. London: Wolfe Publishing Ltd.

Sessle BJ (1987) Neurophysiology of orofacial pain. Dent Clin North Am 4:595-613.

Sessle BJ (2011) Peripheral and central mechanisms of orofacial inflammatory pain. Int Rev Neurobiol 97:179-206.

Shinoda M, Kubo A, Hayashi Y, Iwata K (2019) Peripheral and central mechanisms of persistent orofacial pain. Front Neurosci 13:1227.

Song Y, Zhang YM, Xu J, Wu JR, Qin X, Hua R (2013) [Effect of spontaneous firing of injured dorsal root ganglion neuron on excitability of wide dynamic range neuron in rat spinal dorsal horn.] Sheng $\mathrm{Li}$ Xue Bao 65:533-539.

Spencer CJ, Gremillion HA (2007) Neuropathic orofacial pain: proposed mechanisms, diagnosis, and treatment considerations. Dent Clin North Am 51:209-224.

Tandon OP, Malhotra V, Tandon S, D'Silva I (2003) Neurophysiology of pain: insight to orofacial pain Indian. J Physiol Pharmacol 47: 247-269.

Tashiro A, Bereiter DA, Thompson R, Nishida Y (2014) GABAergic influence on temporomandibular joint-responsive spinomedullary neurons depends on estrogen status. Neuroscience 259:53-62. 
Todd AJ (2010) Neuronal circuitry for pain processing in the dorsal horn. Nat Rev Neurosci 11:823-836.

van der Bilt A, Engelen L, Pereira LJ, van der Glas HW, Abbink JH (2006) Oral physiology and mastication. Physiol Behav 89:22-27.

Wilcox SL, Gustin SM, Macey PM, Peck CC, Murray GM, Henderson LA (2015) Anatomical changes within the medullary dorsal horn in chronic temporomandibular disorder pain. Neuroimage 117:258266.

Wilkinson JL (2014) Neuroanatony for medical students. London: Wright.

Won KA, Kang YM, Lee MK, Park MK, Ju JS, Bae YC, Ahn DK (2012) Participation of microglial p38 MAPK in formalin-induced temporomandibular joint nociception in rats. J Orofac Pain 26:132-141.

Wong $\mathrm{H}$, Kang I, Dong XD, Christidis N, Ernberg M, Svensson P, Cairns BE (2014) NGF-induced mechanical sensitization of the masseter muscle is mediated through peripheral NMDA receptors. Neuroscience 269:232-244.

Woolf CJ, American Physiological Society (2004) Pain: moving from symptom control toward mechanism-specific pharmacologic management. Ann Intern Med 140:441-451.

Yam MF, Loh YC, Tan CS, Khadijah Adam S, Abdul Manan N, Basir R (2018) General pathways of pain sensation and the major neurotransmitters involved in pain regulation. Int J Mol Sci 19:2164.

Yin Y, Yi MH, Kim DW (2018) Impaired autophagy of GABAergic interneurons in neuropathic pain. Pain Res Manag 2018:9185368.

Zhou LJ, Peng J, Xu YN, Zeng WJ, Zhang J, Wei X, Mai CL, Lin ZJ, Liu Y, Murugan M, Eyo UB, Umpierre AD, Xin WJ, Chen T, Li M, Wang H, Richardson JR, Tan Z, Liu XG, Wu LJ (2019) Microglia are indispensable for synaptic plasticity in the spinal dorsal horn and chronic pain. Cell Rep 27:3844-3859.e6. 